\title{
ANALISIS KESESUAIAN WISATA PANTAI JODO DESA SIDOREJO KECAMATAN GRINGSING KABUPATEN BATANG
}

\author{
Conformity Analysis of Jodo Beach Tourism in Sidorejo Village, Gringsing District, Batang \\ Regency
}

Iswaty chasanah ${ }^{\mathrm{a}}$, Pujiono Wahyu Purnomo ${ }^{\mathrm{b}}$ Haeruddin $^{\mathrm{c}}$

\author{
${ }^{a}$ Manajemen Sumberdaya Pantai, Fakultas Perikanan dan Ilmu Kelautan, Universitas Diponegoro, Semarang \\ 50275 —iswatychasanah@gmail.com \\ ${ }^{b}$ Program Manajemen Sumberdaya Pantai, Fakultas Perikanan dan Ilmu Kelautan, Universitas Diponegoro, \\ Semarang 50275 \\ ${ }^{c}$ Program Manajemen Sumberdaya Pantai, Fakultas Perikanan dan Ilmu Kelautan, Universitas Diponegoro, \\ Semarang 50275
}

\begin{abstract}
Jodo beach is located in Sidorejo Village, Gringsing District, Batang Regency. The beach is relatively even and has black sand as an attraction. This research was conducted in December 2016 and aimed to determine Jodo beach tourism conformity as beach tourism area in recreation and swimming category. The method used is primary data and method to determine area conformity by multiplying scores and weights obtained from each parameter in beach tourism conformity index, which included depth, beach type, beach width, clarity, current speed, seabed material, harmful biota observation, and the availability of fresh water. In general, all area of Jodo beach have similar characteristics. The result showed that tourism suitability index for beach tourism in station I was 97\% S1 (highly suitable), station II was 88\% S1 (highly suitable), station III was $82 \%$ S2 (suitable), and station IV was $86 \%$ SI (highly suitable). Therefore, the area was suitable for recreational and swimming activity, and continuous development in the Jodo beach tourism area was possible.
\end{abstract}

Keywords: Jodo beach, tourism object, tourism suitability

(Diterima: 11-02-2017; Disetujui: 10-05-2017)

\section{Pendahuluan}

\subsection{Latar Belakang}

Wisata bahari merupakan salah satu bentuk dari wisata minat khusus yaitu wisata yang memiliki aktifitas terkait dengan dunia bahari atau kelautan. Wisata bahari mengandung unsur yaitu; kegiatan perjalanan, dilakukan secara sukarela, bersifat sementara, perjalanan seluruhnya atau sebagian bertujuan untuk menikmati obyek dan daya tarik wisata khususnya keindahan panorama pesisir dan lautan (Nuraisyah et al., 2004). Wisata bahari juga merupakan suatu kunjungan yang dilakukan oleh seseorang atau sekelompok orang untuk menikmati keindahan laut dan mempunyai tujuan untuk melakukan aktifitas khusus seperti berenang dan atau hanya berjemur di pantai (Yulianda, 2007).

Pembangunan obyek wisata di Indonesia sendiri tidak terlepas dari perkembangan pariwisata dunia yang begitu pesat, hal ini disebabkan oleh kemajuan teknologi yang mendukung akan kemampuan pemenuhan kebutuhan untuk berlibur dengan melakukan kunjungan wisata. Perkembangan arus wisata yang semakin pesat merupakan salah satu bagian dalam pertumbuhan kepariwisataan. Terkait dengan hal tersebut suatu wilayah harus dikemas dengan baik untuk menjawab tantangan arus kunjungan wisatawan yang membutuhkan lokasi sebagai tempat berwisata dengan dukungan sarana dan prasarana wisata. Hal ini merupakan fasilitas dari industri jasa pariwisata yang ditentukan baik atau tidak baiknya kaadaan lokasi baik sarana dan prasarana yang merupakan faktor penunjang kepariwisataan (UU No 10 tahun 2009).

Sektor pariwisata di Indonesia memiliki konstribusi ekonomi yang cukup penting bagi kegiatan pembangunan. Hal ini didukung oleh jumlah kunjungan wisatawan yang mengalami peningkatan. Pada tahun 2011 kunjungan wisatawan mancanegara sebesar 7,649,731, dan meningkat menjadi 10,406,759 pada tahun 2015 (Tabel 1). Dengan demikian wisata menjadi sangat potensial untuk dikembangkan dalam pembangunan jangka menengah dan jangka panjang.

Tabel 1. Jumlah kunjungan wisatawan mancanegara tahun 20112015

\begin{tabular}{cc}
\hline Tahun & Jumlah wisatawan mancanegara \\
\hline 2011 & $7,649,731$ \\
2012 & $8,044,462$ \\
2013 & $8,802,129$ \\
2014 & $9,435,411$ \\
2015 & $10,406,759$ \\
\hline Sumber : Pusdatin Kemenparekraf dan BPS 2011-2015
\end{tabular}

Pembangunan dan pengembangan sektor pariwisata dapat memberikan pengaruh positif, baik secara langsung maupun tidak langsung. Pengaruh langsung dari kegiatan pariwisata adalah berupa penerimaan secara langsung dari para kunjungan wisatawan, sedangkan dampak tidak langsung yaitu meningkatkan 
pendapatan bagi perusahaan penerbangan akibat kunjungan wisatawan dari dalam maupun luar negeri. Dengan demikian, dibutuhkan pengembangan lokasi baru, salah satunya adalah Pantai Jodo di Kabupaten Batang.

Pantai Jodo terletak di desa Sidorejo, Kecamatan Gringsing, Kabupaten Batang yang merupakan salah satu kabupaten di Provinsi Jawa Tengah, Indonesia yang berpotensi dalam pengembangan pariwisata, khususnya wisata pantai. Saat ini Pantai Jodo telah digunakan sebagai daerah rekreasi, taman bermain anak-anak, tanah lapang yang sering digunakan untuk kegiatan berkemah atau camping oleh sekolah, serta obyek wisata lain yang akan dikembangkan oleh Pemerintah Kabupaten Batang. Pantai ini memiliki ciri dengan pesona alam berupa hamparan pasir hitam yang luas ditumbuhi pepohonan cemara laut yang menjadikan karakter tersendiri dari pantai Jodo.Pantai Jodo dikelola oleh Pemerintah Desa dan masyarakat lokal yang bernaung dibawah kelompok sadar wisata (pokdarwis), Pantai Jodo merupakan obyek wisata pilihan masyarakat Desa Sidorejo dan daerah lain yang berada di sekitarnya, minat masyarakat lokal yang terbentuk dalam organisasi pokdarwis berkeinginan mengembangkan pantai Jodo sebagai daerah wisata pantai khususnya sebagai kegiatan rekreasi pantai dan berenang.

Pantai merupakan daerah pertemuan antara laut dan darat, dan merupakan wilayah tempat berinteraksinya kekuatan alam yang berasal dari laut, darat, dan udara, sehingga bersifat dinamis serta selalu berubah. Bentuk pantai yang bersifat dinamis dan selalu berubah dapat diakibatkan oleh faktor alami maupun campur tangan manusia, sehingga diperlukan suatu pengelolaan agar keberadaannya tetap lestari. Salah satu bentuk pemanfaatan sumberdaya pantai yang mengandalkan jasa alam untuk kepuasaan manusia adalah pantai.
Dengan adanya hal ini maka peneliti menggunakan kondisi ekologis untuk melihat potensi kawasan dengan beberapa parameter untuk mendapatkan nilai Indeks Kesesuaian Wisata (IKW) (Hakim et al., 2014) sebagai daerah kegiatan wisata pantai. Maka yang menjadi permasalahan apakah kawasan Pantai Jodo dapat digunakan sebagai kawasan wisata pantai?

\subsection{Tujuan penelitian}

Tujuan dari penelitian ini yaitu untuk menganalisis kesesuaian wisata pantai sebagai tempat rekreasi pantai dan berenang.

\section{Metode}

\subsection{Waktu dan Lokasi Penelitian}

Penelitian ini dilaksanakan pada bulan Desember 2016 di kawasan Pantai Jodo Kecamatan Gringsing Kabupaten Batang Jawa Tengah. Lokasi Pantai Jodo berada pada daerah paling timur Batang dan bersebelahan dengan Kabupaten Kendal, sebelah selatan berbatasan dengan Kecamatan Tersono, dan sebelah barat berbatasan dengan Kecamatan Banyuputih. Lokasi pengambilan data di bagi menjadi 4 stasiun dengan stasiun I berada pada titik koordinat $06^{0} 55^{\prime} 19,51^{\prime} \mathrm{S}$ dan $109^{0} 59^{\prime} 50,09^{\prime} \mathrm{T}$, stasiun II berada pada titik koordinat $06^{0} 55^{\prime} 19,23$ 'S dan $109^{0} 59^{\prime} 53,34^{\prime \prime} \mathrm{T}$, stasiun III berada pada titik koordinat $06^{0} 55^{\prime} 18,51^{\prime \prime} \mathrm{S}$ dan $109^{0} 59^{\prime} 56,50^{\prime \prime} \mathrm{T}$, selanjutnya pada stasiun IV berada pada titik koordinat $06^{0} 55^{\prime} 17,37$ 'S dan 109059'59,54'T. Pantai Jodo terletak tidak jauh dari kota Semarang, perjalanan ditempuh melalui jalur darat dengan waktu \pm 2 jam dari Kota Semarang.

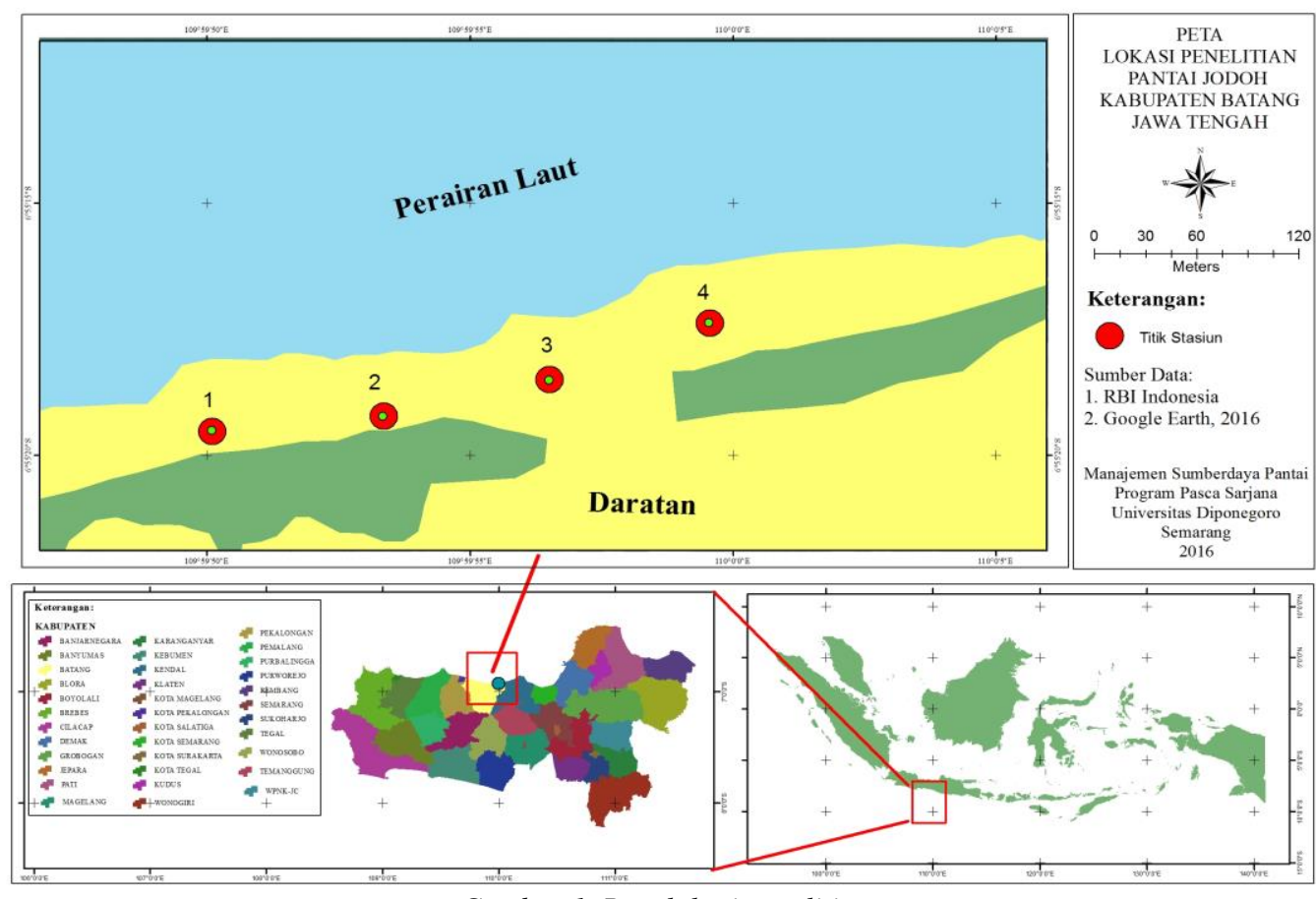

Gambar 1. Peta lokasi penelitian 


\subsection{Alat dan Bahan}

Alat dan bahan yang digunakan dalam penelitian ini adalah alat tulis, kamera, stopwatch, Global Poseitioning System (GPS), secchi disk, roll meter, bola pimpong/bola arus, vanveen grap,dan tongkat ukur.

\subsection{Teknik Pengumpulan Data}

Penelitian ini menggunakan data primer dengan metode survei dan pengukuran langsung di lapangan. Pengumpulan data dilakukan di daerah pantai dengan cara purposive sampling yaitu berdasarkan keterwakilan wilayah dari pengamatan secara langsung di lapangan. Lokasi penelitian dibagi atas 4 stasiun untuk wisata rekreasi pantai dan berenang. Pengambilan contoh 4 stasiun berdasarkan keterwakilan wilayah dari pengamatan secara langsung di lapangan dengan pertimbangan bahwa di daerah tersebut sering digunakan oleh wisatawan sebagai lokasi kegiatan wisata rekreasi pantai dan berenang. Pengambilan data pada ke 4 stasiun dilakukan dengan tahap penentuan titik koordinat menggunakan Global Positioning System (GPS) untuk melihat posisi lokasi stasiun, selanjutnya dilakukan pengukuran kesepuluh parameter kesesuaian wisata pantai di masing-masing stasiun dan pencatatan hasilnya untuk selanjutnya di analisis.

\subsection{Cara Pengukuran}

\section{a. Kedalaman perairan}

Pengukuran kedalaman menggunakan alat tongkat ukur atau tiang skala yang panjangnya 5 meter, nilai yang ditunjukkan pada tongkat ukur merupakan nilai kedalaman stasiun penelitian dan penentuan kedalaman lokasi pengambilan data berjarak 100 meter dari garis pantai yang dianggap aman untuk kegiatan wisata karena tidak ada batasan jarak seseorang melakukan kegiatan berenang di pantai.

\section{b. Tipe pantai}

Penentuan tipe pantai dilakukan secara pengamatan visual, yaitu dengan mengamati jenis dan warna pasirnya.

\section{c. Lebar pantai}

Lebar pantai dilakukan menggunakan roll meter, yaitu jarak antara vegetasi terakhir dari darat dengan batas surut terendah pada saat pengambilan sampel.

\section{d. Supsrat dasar perairan}

Menentukan supsrat dasar perairan dengan cara mengambil supsrat dasar perairan menggunakan Van veen grab di setiap titik sampling kemudian dilakukan pengamatan secara visual di lapangan, kemudian menggolongkan apakah termasuk supsrat pasir, atau pasir berkarang (Kamah et al., 2013; Yulisa et at, 2016).

\section{e. Kecepatan arus}

Pengukuran kecepatan arus yaitu dengan menetapkan jarak tempuh bola arus (1 meter) kemudian di ukur waktu tempuh bola arus tersebut menggunakan stopwatch. Kecepatan arus dapat diketahui menggunakan rumus (Suryadhi, 2013) sebagai berikut:

$$
\mathrm{V}=\mathrm{S} / \mathrm{T}
$$

Keterangan:

$\mathrm{V}=$ Kecepatan arus $(\mathrm{m} / \mathrm{s})$

$\mathrm{S}=\operatorname{Jarak}(\mathrm{m})$

$\mathrm{T}=$ Waktu (detik)

\section{f. Kemiringan pantai}

Pengukuran kemiringan pantai dapat diketahui dengan melihat kedalaman pantai maka akan diketahui sudut kemiringan pantai. Hitung ketinggian tongkat atau kedalaman pantai kemudian tarik garis lurus dengan bantuan rollmeter, kemudian akan didapatkan sudut kemiringan pantai tersebut dengan menggunakan rumus Lestari (2013):

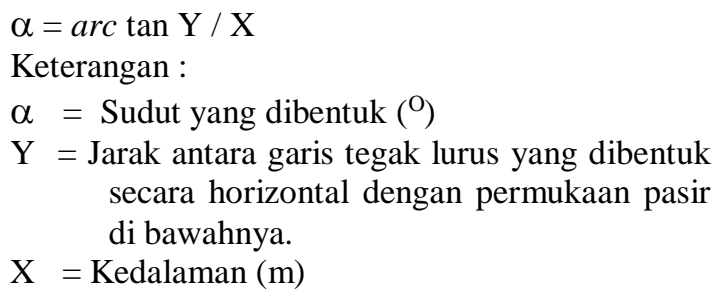

\section{g. Kecerahan perairan}

Pengukuran kecerahan dilakukan menggunakan secchi disk yang diikat dengan tali kemudian diturunkan perlahan ke dalam perairan pada lokasi pengamatan. Perhitungan dilakukan menggunakan rumus Khairuman (2007):

Kecerahan air $(\mathrm{cm})=$ jarak tidak tampak + jarak tampak

\section{2}

\section{h. Penutupan lahan}

Penentuan penutupan lahan dilakukan dengan mengamati daerah sekitar pantai, kemudian menggolongkan apakah lahan terbuka dengan pohon kelapa, savana, semak belukar, atau permukiman.

\section{i. Biota berbahaya}

Penentuan biota berbahaya dilakukan dengan mengamati biota-biota yang ada di pantai Jodo pada saat sampling, dengan indikator bulu babi, ikan pari, ular laut, dan ikan berbisa yang menjadi biota berbahaya karena biota laut ini memiliki duri dan racun yang berbahaya bagi manusia. 


\section{j. Ketersediaan air tawar}

Pengukuran ini dilakukan secara visual dan juga pengukuran, yaitu dengan cara mengamati sumber air tawar yang terdekat dari pantai yang digunakan oleh pengelola untuk menjadi sumber air bersih. Kemudian, jarak antara pantai dengan sumber air di ukur.

\subsection{Desain Penelitian}

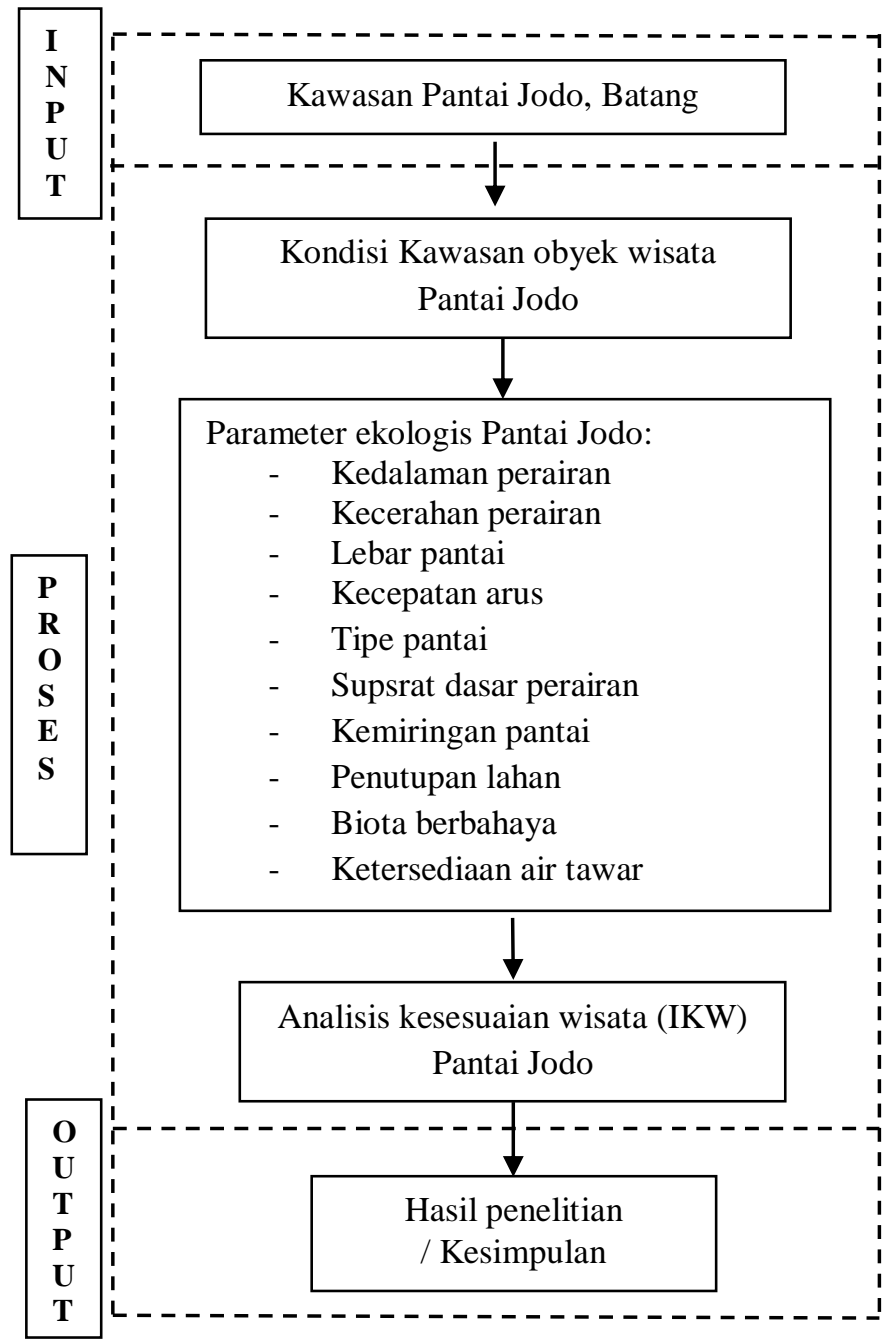

Gambar 2. Skema pendekatan masalah dalam penelitian

\subsection{Tahapan Cara Kerja}

Tahapan penelitian dimulai dari survei lokasi pada bulan Oktober 2016 di kawasan Pantai Jodo Desa Sidorejo, Kecamatan Gringsing, Kabupaten Batang Provinsi Jawa Tengah. Survei dilaksanakan guna mengetahui kondisi pantai serta keinginan masyarakat lokal untuk menjadikan Pantai Jodo sebagai daerah wisata, khususnya wisata kategori rekreasi dan berenang, kemudian dilanjutkan dengan penelitian pada bulan Desember 2016.

Pengambilan data parameter kesesuaian lahan sebagai daerah rekreasi pantai dan berenang dengan menentukan 4 titik sampling/ stasiun dengan pertimbangan bahwa di daerah tersebut sering digunakan oleh wisatawan untuk melakukan kegiatan wisata rekreasi pantai dan berenang. Pada setiap stasiun dilakukan pengambilan titik koordinat menggunakan Global Positioning System (GPS) untuk mengetahui posisi lokasi pengambilan data.

Pengambilan data primer dilakukan dengan mengukur parameter kesesuaian lahan yang terdiri dari kedalaman perairan, lebar pantai, tipe pantai, supsrat dasar perairan, kecerahan perairan, kecepatan arus, kemiringan pantai, penutupan lahan, biota berbahaya, dan ketersediaan air tawar pada tiap-tiap titik sampling atau pada tiap stasiun yang telah ditentukan (Tabel 2). Dari data primer tersebut kemudian dianalisis menggunakan analisis indeks kesesuaian wisata (IKW) pantai kategori rekreasi pantai dan berenang (Yulianda 2007; Indarjho, 2012) untuk mengetahui apakah kawasan Pantai Jodo dapat digunakan sebagai obyek wisata pantai guna memenuhi kebutuhan masyarakat lokal maupun masyarakat yang berada di sekitar daerah Pantai Jodo.

\subsection{Parameter Penelitian}

Parameter yang diamati untuk kesesuaian wisata kategori rekreasi pantai dan berenang terdiri dari 10 parameter (Tabel 2).

Tabel 2. Parameter Indeks Kesesuaian Wisata Pantai (IKW)

\begin{tabular}{|c|c|c|c|c|c|c|c|}
\hline Parameter & Bobot & Kategori S1 & Skor & Kategori S2 & Skor & Kategori S3 & Skor \\
\hline Kedalaman perairan $(\mathrm{m})$ & 5 & $0-3$ & 3 & $>3-5$ & 2 & $>5$ & 1 \\
\hline Tipe pantai & 5 & Pasir putih & 3 & $\begin{array}{c}\text { Pasir putih sedikit } \\
\text { karang }\end{array}$ & 2 & $\begin{array}{c}\text { Pasir putih berkarang } \\
\text { sedikit terjal }\end{array}$ & 1 \\
\hline Lebar pantai (m) & 5 & $>30$ & 3 & $10-30$ & 2 & $3-<10$ & 1 \\
\hline Supsrat dasar perairan & 3 & Pasir & 3 & Karang berpasir & 2 & Pasir berkarang, berbatu & 1 \\
\hline Kecepatan arus (m/s) & 3 & $0-0,2$ & 3 & $>0,2-0,4$ & 2 & $>0,4$ & 1 \\
\hline Kemiringan pantai $\left({ }^{0}\right)$ & 3 & $<10$ & 3 & $10-25$ & 2 & $>25$ & 1 \\
\hline Kecerahan pantai & 1 & $>5$ & 3 & $>3-10$ & 2 & $<3$ & 1 \\
\hline Penutupan lahan & 1 & $\begin{array}{l}\text { Lahan terbuka, } \\
\text { kelapa }\end{array}$ & 3 & $\begin{array}{c}\text { Semak belukar, } \\
\text { savana }\end{array}$ & 2 & $\begin{array}{c}\text { Belukar tinggi, } \\
\text { pemukiman, pelabuhan }\end{array}$ & 1 \\
\hline Biota berbahaya & 3 & Tidak ada & 3 & Satu spesies & 2 & Lebih dari satu spesies & 1 \\
\hline $\begin{array}{c}\text { Ketersediaan air tawar } \\
(\mathrm{km})\end{array}$ & 1 & $<0,5$ & 3 & $<0,5-1$ & 2 & $>1-2$ & 1 \\
\hline
\end{tabular}




\subsection{Analisis data}

Analisis data menggunakan matriks kesesuaian atau Indeks Kesesuaian Wisata (IKW) yang disusun berdasarkan kepentingan setiap parameter untuk mendukung kegiatan pada daerah tersebut. Rumus yang digunakan untuk kesesuaian wisata pantai adalah (Yulianda, 2007; Indarjho, 2012)

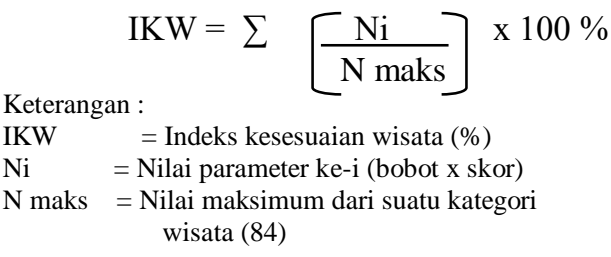

Berdasarkan matriks kesesuaian, selanjutnya dilakukan penyusunan kelas-kelas kesesuaian untuk kegiatan wisata rekreasi pantai dan berenang. Kelas kesesuaian dibagi menjadi 4 kelas kesesuaian meliputi:

S1 = Sangat sesuai dengan nilai 83-100\%

$\mathrm{S} 2=$ Sesuai dengan nilai $50-<83 \%$

$\mathrm{S} 3=$ Sesuai bersyarat dengan nilai $17-<50 \%$

$\mathrm{TS}=$ tidak sesuai dengan nilai $<17 \%$

Skala yang digunakan untuk mengisi kolom dalam menentukan bobot adalah sebagai berikut:

1. Pemberian bobot 5: didasarkan pada pemikiran bahwa parameter ini sangat diperlukan atau parameter kunci.

2. Pemberian bobot 3 : didasarkan pada pemikiran bahwa parameter ini diperlukan.

3. Pemberian bobot 1 : didasarkan pada pemikiran bahwa parameter ini dalam penelitian tidak begitu diperlukan atau parameter kurang penting, yang artinya tanpa adanya parameter ini kegiatan wisata masih bisa berjalan.

Pemberian skor berdasarkan kualitas parameter kesesuaian selama proses pengambilan data di lapangan. Kriteria untuk masing-masing skor adalah: a. Pemberian skor 3: kondisi parameter yang baik b. Pemberian skor 2: kondisi parameter memiliki kualitas cukup baik

c. Pemberian skor 1 : kondisi parameter memiliki kualitas yang buruk

\section{Hasil dan Pembahasan}

\subsection{Kondisi Pantai Jodo}

Sebagai daerah tujuan wisata, Kabupaten Batang memiliki potensi dan daya tarik wisata yang sangat beragam, salah satunya Pantai Jodo yang merupakan bagian paling timur dari daerah Kabupaten Batang yang merupakan daerah dataran rendah dan daerah pesisir. Pantai yang terkenal di Kabupaten Batang antara lain Pantai Ujung Negoro dan Pantai Sigandu, sedangkan Pantai Jodo merupakan pantai yang baru dikelola oleh Pokdarwis dan pemerintah desa.

Para wisatawan yang akan berkunjung ke Pantai Jodo dapat menggunakan kendaraan roda empat, ataupun kendaraan roda dua. Jalur dari arah Semarang melewati jalan pantura menuju Kecamatan Gringsing, Kabupaten Batang selanjutnya dilanjutkan ke Desa Sidorejo dimana lokasi Pantai Jodo berada. Pengunjung yang menggunakan kendaraan mobil di kenakan tarif Rp. 5.000,- untuk sepeda motor Rp. 3.000,-. Tiket masuk dikenakan biaya Rp. 3.000,-- per orang sesuai dengan surat keputusan Bupati Batang Nomor 71 tahun 2016 tentang retribusi tempat rekreasi dan olahraga. Penarikan tiket dilakukan oleh warga setempat yang bernaung di bawah kelompok sadar wisata (Pokdarwis) Pantai Jodo. Hasil dari retribusi di bagi untuk pemerintah (Dinas Pariwisata dan Kebudayaan) $40 \%$ dan $60 \%$ milik warga setempat sebagai kas desa.

Penyediaan dan pembangunan sarana dan prasarana yang lain sangat penting jika berkaitan dengan adanya wisata demi meningkatkan kenyamanan bagi pengunjung. Kondisi sarana dan prasarana di kawasan Pantai Jodo dapat dilihat pada tabel 3 di bawah ini.

\begin{tabular}{|c|c|c|c|}
\hline No & Jenis sarana prasarana & Fisik & Keterangan \\
\hline \multirow[t]{9}{*}{1.} & Fasilitas wisata & & \\
\hline & 1. Areal parkir & - & $\begin{array}{l}\text { Belum ada tempat khusus sebagai areal parkir sehingga belum tertata } \\
\text { rapi, maka perlu dilakukan pembangunan areal parkir. }\end{array}$ \\
\hline & 2. Kamar mandi / WC & 4 unit & $\begin{array}{l}\text { Kurang perawatan untuk kebersihan karena dibersihkan hanya pada } \\
\text { hari tertentu saja yaitu hari saptu dan senin. }\end{array}$ \\
\hline & Tempat ibadah & 1 unit & Kondisi baik \\
\hline & Penginapan & - & Belum ada tempat penginapan \\
\hline & 5. Kios/ warung makan & 18 unit & $\begin{array}{l}\text { Sarana ini diusahakan sendiri oleh penduduk sekitar sebagai warung } \\
\text { makan. }\end{array}$ \\
\hline & Tempat sampah & 16 unit & Kondisi baik \\
\hline & 7. Tempat pertemuan & 1 unit & Kondisi baik \\
\hline & 8. Taman bermain & 1 unit & $\begin{array}{l}\text { Taman bermain anak-anak yang ada di kawasan Pantai Jodo } \\
\text { kondisinya baik }\end{array}$ \\
\hline \multirow[t]{2}{*}{2.} & Fasilitas pendukung & & \\
\hline & $\begin{array}{l}\text { Jalan menuju Pantai } \\
\text { Jodo }\end{array}$ & & $\begin{array}{l}\text { Perjalanan menuju lokasi berjarak } 10 \mathrm{~km} \text { dari jalan raya pantura, lebar } \\
\text { jalan } \pm 3 \text { meter dibatasi oleh pemukiman, persawahan dan kebun. } \\
\text { Kondisi kurang baik, walaupun sudah pernah di lakukan pengaspalan } \\
\text { tetapi sekarang terdapat kerusakan pada beberapa titik. }\end{array}$ \\
\hline
\end{tabular}


Tabel 4. Hasil Indeks kesesuaian wisata Pantai di Pantai Jodo kabupaten Batang

\begin{tabular}{|c|c|c|c|c|c|c|c|c|c|c|c|c|c|c|}
\hline \multirow{2}{*}{ No } & \multirow{2}{*}{ Parameter } & \multirow{2}{*}{ Bobot } & \multicolumn{12}{|c|}{ Keterangan } \\
\hline & & & Stasiun 1 & Skor & Jumlah & Stasiun 2 & Skor & Jumlah & Stasiun 3 & Skor & Jumlah & Stasiun 4 & Skor & Jumlah \\
\hline 1. & $\begin{array}{l}\text { Kedalaman } \\
\text { perairan }(\mathrm{m})\end{array}$ & 5 & 1 & 3 & 15 & 0,5 & 3 & 15 & 1 & 3 & 15 & 1,5 & 3 & 15 \\
\hline 2. & Tipe pantai & 5 & $\begin{array}{l}\text { Pasir } \\
\text { hitam }\end{array}$ & 3 & 15 & $\begin{array}{l}\text { Pasir } \\
\text { hitam }\end{array}$ & 3 & 15 & $\begin{array}{l}\text { Pasir } \\
\text { hitam }\end{array}$ & 3 & 15 & $\begin{array}{l}\text { Pasir } \\
\text { hitam }\end{array}$ & 3 & 15 \\
\hline 3. & $\begin{array}{l}\text { Lebar pantai } \\
\text { (m) }\end{array}$ & 5 & 35 & 3 & 15 & 20 & 2 & 10 & 8,5 & 1 & 5 & 17 & 1 & 5 \\
\hline 4. & $\begin{array}{l}\text { Supsrat } \\
\text { dasar } \\
\text { perairan }\end{array}$ & 3 & Pasir & 3 & 9 & Pasir & 3 & 9 & Pasir & 3 & 9 & Pasir & 3 & 9 \\
\hline 5. & $\begin{array}{l}\text { Kecepatan } \\
\text { arus }(\mathrm{m} / \mathrm{s})\end{array}$ & 3 & 0,2 & 3 & 9 & 0,3 & 2 & 6 & 0,3 & 2 & 6 & 0,3 & 3 & 9 \\
\hline 6. & $\begin{array}{l}\text { Kemiringan } \\
\text { pantai }\left(\left(^{0}\right)\right.\end{array}$ & 3 & 1,14 & 3 & 9 & 0,6 & 3 & 9 & 1,14 & 3 & 9 & 1,72 & 3 & 9 \\
\hline 7. & $\begin{array}{l}\text { Kecerahan } \\
\text { perairan }(\mathrm{m})\end{array}$ & 1 & 0,17 & 1 & 1 & 0,07 & 1 & 1 & 0,12 & 1 & 1 & 0,07 & 1 & 1 \\
\hline 8. & $\begin{array}{l}\text { Penutupan } \\
\text { lahan }\end{array}$ & 1 & $\begin{array}{c}\text { Lahan } \\
\text { terbuka, } \\
\text { pohon } \\
\text { cemara }\end{array}$ & 3 & 3 & $\begin{array}{l}\text { Lahan } \\
\text { terbuka, } \\
\text { pohon } \\
\text { cemara }\end{array}$ & 3 & 3 & $\begin{array}{l}\text { Lahan } \\
\text { terbuka, } \\
\text { pohon } \\
\text { cemara }\end{array}$ & 3 & 3 & $\begin{array}{c}\text { Lahan } \\
\text { terbuka, } \\
\text { pohon } \\
\text { cemara }\end{array}$ & 3 & 3 \\
\hline 9. & $\begin{array}{l}\text { Biota } \\
\text { berbahaya }\end{array}$ & 1 & $\begin{array}{c}\text { Tidak } \\
\text { ada }\end{array}$ & 3 & 3 & $\begin{array}{c}\text { Tidak } \\
\text { ada }\end{array}$ & 3 & 3 & $\begin{array}{c}\text { Tidak } \\
\text { ada }\end{array}$ & 3 & 3 & $\begin{array}{c}\text { Tidak } \\
\text { ada }\end{array}$ & 3 & 3 \\
\hline 10 & $\begin{array}{l}\text { Ketersediaan } \\
\text { air tawar } \\
(\mathrm{km})\end{array}$ & 1 & 0,15 & 3 & 3 & 0,20 & 3 & 3 & 0,10 & 3 & 3 & 0,25 & 3 & 3 \\
\hline Tot & $(\mathrm{Ni})$ & & & & 82 & & & 74 & & & 69 & & & 72 \\
\hline Ind & Kesesuaian W & ata $(\%)$ & & & 97 & & & 88 & & & 82 & & & 86 \\
\hline Krit & & & & & S1 & & & $\mathrm{S} 1$ & & & $\mathrm{~S} 2$ & & & $\mathrm{~S} 1$ \\
\hline
\end{tabular}

Sumber : Data Primer diolah (2017)

Keterangan :

$\mathrm{S} 1=$ Sangat sesuai dengan nilai $83-100 \%$

$\mathrm{S} 2=$ Sesuai dengan nilai $50-<83 \%$

$\mathrm{S} 3=$ Sesuai bersyarat dengan nilai $17-<50 \%$

TS = tidak sesuai dengan nilai $<17 \%$

\subsection{Indeks Kesesuaian Wisata (IKW) Pantai Jodo}

\section{a. Kedalaman perairan}

Dari hasil pengukuran keempat stasiun tersebut kedalaman perairan di Pantai Jodo sebagai wisata pantai menunjukan pantai ini termasuk perairan yang dangkal dengan kedalaman rata-rata adalah 1 meter dari ke-4 stasiun. Stasiun tersebut dianggap layak dijadikan area berenang karena kedalaman maksimal 3 meter dalam matriks kesesuaian, sehingga kedalam Pantai Jodo mendapat skor 3 dengan kondisi parameter yang baik.

Kedalaman Pantai Jodo termasuk dalam kategori sangat sesuai untuk wisata rekreasi pantai dan berenang karena kedalaman yang dangkal ini disebabkan berdekatan dengan adanya sungai Mbuntu yang memang tidak pernah di keruk sehingga mengalami pendangkalan. Selain itu kedalaman merupakan faktor penting untuk wisatawan dapat melakukan kegiatan bermain air dengan aman. Menurut Tambunan et al., (2013) para pengunjung biasanya berenang di kedalaman tidak lebih dari 1,5 meter antisipasi terhadap keamanan dalam berenang.

\section{b. Tipe Pantai}

Tipe pantai dapat dilihat dari jenis substrat atau sedimen yang didukung dengan pengamatan secara visual. Berdasarkan jenisnya pantai dibedakan menjadi pantai berpasir, pantai berbatu, dan pantai berkarang. Pantai yang memiliki tekstur pasir pantai yang halus menjadi salah satu faktor penting dalam berwisata rekreasi pantai jika dibandingkan pantai berbatu dan berkarang.

Berdasarkan pengamatan visual Pantai Jodo tergolong kedalam jenis pantai berpasir hitam. Indahnya pasir hitam Pantai Jodo menjadi daya tarik untuk memanjakan wisatawan yang ingin menikmati suasana pantai, dan hal ini juga sesuai dengan matrik kesesuaian (Yulianda, 2007; Indarjho, 2012) bahwa hal ini sangat sesuai sebagai daerah rekreasi pantai dan berenang.

\section{c. Lebar Pantai}

Lebar pantai dilakukan menggunakan roll meter, yaitu jarak antara vegetasi terakhir yang ada di pantai dengan batas surut terendah. Pengukuran lebar pantai dimaksudkan untuk mengetahui seberapa besar wilayah pantai yang dapat digunakan untuk berbagai kegiatan wisata pantai.

Hasil pengukuran di empat stasiun Pantai Jodo menunjukan lebar pantai tergolong cukup lebar dengan rata-rata 20 meter. lebar pantai berkaitan dengan luasan lahan yang dapat dimanfaatkan berbagai kegiatan rekreasi pantai. Karena kondisi lebar pantai yang luas dapat membuat pengunjung lebih leluasa melakukan aktifitas. 
Menurut Haris (2003) dengan panjang garis pantai dan lebar pantai yang cukup panjang dengan hamparan pasir hitam sangat memungkinkan untuk melakukan aktivitas disepanjang pantai tersebut baik untuk kegiatan rekreasi seperti sarana bermain bagi pengunjung terutama anak-anak, berjemur, dan kegiatan wisata yang lain.

\section{d. Supsrat Dasar Perairan}

Berdasarkan pengamatan visual tentang supsrat dasar perairan pada ke empat stasiun di Pantai Jodo memiliki supsrat dasar perairan berupa pasir. Suprat dasar perairan sesuai dengan matrik kesesuaian di mana suprat dasar berpasir paling ideal untuk menunjang aktivitas tersebut. Supsrat dasar perairan merupakan parameter penting dalam mengetahui kesesuaian wilayah khususnya wilayah pantai. Salah satu faktor penting dalam wisata pantai adalah kenyamanan pengunjung bermain pasir.

Pasir yang tergolong halus akan memberikan kenyamanan jika dijadikan pijakan kaki. Selain itu, akan memberikan keamanan bagi pengunjung yang berenang atau hanya bermain air karena tidak harus khawatir kakinya terluka. Kamah et al., (2013) berpendapat bahwa pantai berpasir merupakan pantai yang didominasi oleh hamparan atau daratan pasir, baik yang berupa pasir hitam, abu-abu atau putih. Berdasarkan analisa dengan matrik sesesuaian lahan untuk wisata pantai maka semua stasiun masuk kriteria sangat sesuai.

\section{e. Kecepatan Arus}

Informasi tentang arus sangat berguna dalam berbagai kepentingan seperti pertimbangan dalam pemilihan lokasi pembuatan bangunan dekat pantai. Kecepatan arus juga berhubungan dengan keamanan dan kenyamanan berwisata karena kecepatan arus yang terlalu tinggi dapat membahayan pengunjung mengingat tidak adanya pembatasan kawasan yang diperbolehkan untuk berenang, maka parameter ini sangat penting untuk diukur kesesuaianya.

Hasil yang diperoleh dari pengamatan langsung dilapangan bahwa kecepatan arus di stasiun I berkisar $0.2 \mathrm{~m} / \mathrm{s}$ stasiun II $0.3 \mathrm{~m} / \mathrm{s}$ stasiun III $0.3 \mathrm{~m} / \mathrm{s}$ dan pada stasiun IV $0.3 \mathrm{~m} / \mathrm{s}$, sehingga kecepatan arus di Pantai Jodo termasuk relatif sedang dengan rata-rata $0.28 \%$. Tambunan, et al (2013) mengemukakan bahwa penggolongan kecepatan arus terdiri atas 4 kategori yaitu kategori arus lambat dengan kecepatan pada kisaran $0-0.25 \mathrm{~m} / \mathrm{s}$, kategori arus sedang dengan kecepatan pada kisaran $0.25-0.50 \mathrm{~m} / \mathrm{s}$, kategori arus cepat dengan kecepatan pada kisaran 0.5-1 m/s dan kategori arus sangat cepat dengan kecepatan diatas 1 $\mathrm{m} / \mathrm{s}$.

\section{f. Kemiringan Pantai}

Kemiringan pantai berhubungan dengan arus yang datang dari laut. Menurut Umar (2012) semakin mendekati garis pantai, kelandaian gelombang datang akan semakin curam seiring dengan berkurangnya kedalaman dan akhirnya gelombang akan pecah. Pemecahan gelombang ini membawa dampak positif bagi kenyamanan wisatawan untuk melakukan rekreasi dipinggiran pantai.

Pengamatan kemiringan pantai dilakukan menggunakan tongkat ukur, meteran, dan waterpass. Hasil pengukuran di empat stasiun menunjukan kemiringan Pantai Jodo termasuk dalam kategori pantai yang landai dengan rata-rata kemiringan pantai $0,55^{\circ}$. Wisatawan sebagian besar menyukai pantai yang landai yang kurang dari $10^{\circ}$ dianggap paling sesuai untuk wisata pantai. Sunarto (1991) menambahkan kemiringan pantai merupakan faktor yang mempengaruhi keamanan pengunjung dalam melakukan aktifitas wisata pantai sehingga kemiringan lereng yang datar sampai landai sangat sesuai untuk kegiatan wisata.

\section{g. Kecerahan Perairan}

Selain menjadi parameter kualitas air, kecerahan juga menjadi parameter dalam kesesuaian wisata yaitu untuk menjadi parameter yang mencirikan keindahan nilai keindahan pemandangan saat melakukan kegiatan berwisata. Namun karena di kawasan Pantai Jodo berdekatan dengan keluar masuknya air sungai dan sedimen dari daratan yang terbawa oleh aliran air sungai menyebabkan warna perairan dikawasan pantai ini menjadi keruh dan kurang menarik.

Berdasarkan pengamatan langsung diperoleh bahwa kecerahan perairan di Pantai Jodo menunjukkan hasil yang rendah dengan rata-rata kecerahan 0.13 meter. Namun, nilai kecerahan tersebut tergolong baik mengingat kedalaman perairan yang di amati berkisar 1.5-2 meter. Hal ini disebabkan oleh material dari daratan yang terbawa oleh aliran air sungai mbuntu yang bersebelahan dengan Pantai Jodo selain itu cuaca saat pengukuran juga sangat menentukan tingginya kecerahan di perairan, karena cahaya matahari masuk ke perairan memiliki nilai yang hampir mendekati dengan kedalaman perairan sehingga perairan Pantai Jodo masih baik untuk aktifitas wisata pantai.

\section{h. Penutupan Lahan}

Penutupan lahan pantai adalah pemanfaatan yang dikelola terhadap kawasan disekitar pantai. Dari ke empat stasiun penutupan lahan di Pantai Jodo merupakan lahan terbuka yang ditumbuhi oleh pohon cemara laut dan selebihnya merupakan lahan terbuka. Hal ini menjadi daya tarik tersendiri karena menjadi ciri khas pantai Jodo yang di sepanjang pantai ditumbuhi oleh pohon cemara laut.

Pengelolaan penutupan lahan pantai bertujuan untuk meningkatkan daya tarik wisata di kawasan pantai dan pengelolaan yang baik akan menghasilkan kelestarian kawasan sehingga perlu diperhatikan untuk 
tetap menjaga agar penutupan lahan di Pantai Jodo dikelola dengan baik. Penutupan lahan dalam matrik kesesuaian wisata kategori rekreasi dan berenang terbagi menjadi lahan terbuka dan kelapa, semak belukar tinggi dan semak belukar rendah, pemukiman dan pelabuhan. Wilayah Pantai Jodo terdapat penutupan lahan terbuka dengan vegetasi pohon cemara laut di ke empat stasiun yang secara tidak langsung memberikan pemandangan pohon cemara yang rindang dan hijau serta pemandangan dengan hamparan pasir yang sering dijadikan tempat bermain, istirahat para pengunjung pantai.

\section{i. Biota Berbahaya}

Biota berbahaya merupakan faktor penting dalam wisata baik rekreasi maupun berenang. Semakin sedikit biota berbahaya yang ditemukan maka lokasi tersebut akan semakin baik. Biota yang menjadi indikator adalah bulu babi, ikan pari, ular laut, dan ikan berbisa. Dari hasil pengamatan secara visual tidak ditemukan Keberadaan biota berbahaya yang dijumpai di kawasan Pantai Jodo sehingga kawasan ini aman untuk menunjang kegiatan berenang berkaitan dengan aspek keamanan dan kenyamanan pengunjung.

Apabila pada suatu kawasan terdapat biota berbahaya seperti bulu babi atau ikan pari akan mengurangi tingkat keamanan pengunjung, bahkan bisa mengurangi intensitas jumlah pengunjung yang datang. Tidak demikian dengan Pantai Jodo, berdasarkan hasil pengamatan pada saat pengambilan data kesesuaian lahan tidak ditemukan adanya biota berbahaya di kawasan Pantai Jodo. maka dapat disimpulkan bahwa menurut teori (Yulianda, 2007; Indarjho, 2012) masuk kategori sangat sesuai sebagai Kawasan Wisata Pantai khususnya kategori rekreasi pantai dan berenang.

\section{j. Ketersediaan Air Tawar}

Ketersediaan air tawar merupakan salah satu parameter dalam suatu penilaian kesesuaian terlebih wisata pantai. Kebutuhan air tawar baik untuk dikonsumsi maupun membersihkan diri setelah berwisata. Ketersediaan air tawar yang berada di sekitar Pantai Jodo dapat diperoleh melalui jarak 0,15 $\mathrm{km}$ atau 150 meter pada stasiun I, stasiun II berjarak $0,20 \mathrm{~km}$ atau 200 meter, stasiun III berjarak $0,10 \mathrm{~km}$ atau 100 meter dan pada stasiun IV berjarak $0,25 \mathrm{~km}$ atau 250 meter. Perbedaan jarak ini disebabkan oleh letak kamar mandi/ toilet terletak dekat stasiun I dan II sedangkan kamar mandi/ wc yang lain berdekatan dengan stasiun III dan IV.

Stasiun I, II, III, dan IV dalam penelitian ini memiliki akses yang paling sesuai dengan ketersediaan air tawar dimana jarak tempuh $<500$ meter. Dalam matrik kesesuaian wisata jarak ketersediaan air tawar yang paling sesuai untuk wisata pantai kategori rekreasi dan berenang adalah $<500$ meter atau $0,5 \mathrm{~km}$. Ketersediaan air bersih berupa air tawar diperlukan untuk menunjang fasilitas pengelolaan maupun pelayanan ekowisata. Hal ini merupakan kriteria penilaian terhadap kelayakan prioritas pengembangan ekowisata pantai (Handayawati et al., 2010).

Maka dari kesepuluh parameter ini, Pantai Jodo yang terletak di Desa Sidorejo Kecamatan Gringsing Kabupaten Batang cocok dikembangkan sebagai daerah wisata pantai khususnya rekreasi pantai dan berenang.

\section{Kesimpulan}

Dari hasil penelitian maka dapat disimpulkan bahwa kawasan Pantai Jodo secara umum memiliki karakteristik yang hampir sama, hal ini dapat dilihat dari hasil persentase kesesuaian pada stasiun I sampai IV tidak jauh berbeda. Indeks kesesuaian wisata (IKW) dari penilaian semua parameter kesesuaian wisata, stasiun I memiliki nilai persentase $98 \%$, stasiun II $88 \%$, stasiun III $82 \%$, dan pada stasiun IV 91\%. Berdasarkan indeks kesesuaian wisata secara umum stasiun I, II, dan IV pada penelitian ini yang berada di Pantai Jodo sangat sesuai (S1) untuk wisata pantai kategori rekreasi dan berenang, sedangkan pada stasiun III termasuk kategori sesuai (S2; Tabel 4).

\section{Daftar Pustaka}

[1] Hakim, A., Setiono, P. Ningtias, Tasrif, Sudarsono, Ari, Yanda, W. Puji, Pertiwi, Jupri, Dista, Anita, dan Yoppie, 2014. Pedoman Penyusunan Rencana Teknis Pemanfaatan Kawasan Konservasi Perairan. Direktorat Konservasi Kawasan dan Jenis Ikan, Direktorat Jenderal Kelautan, Pesisir dan Pulau-Pulau Kecil, Jakarta.

[2] Handayawati, H., Budiono, dan Soemarno, 2010. Potensi Wisata Alam Pantai-Bahari. PM PSLP PPSUB.

[3] Haris, A., 2003. Analisis Kesesuaian Lahan dan Kebijakan Pemanfaatan Ruang Wilayah Pesisir Teluk Kayeli Kabupaten Buru. Tesis. Sekolah Pascasarjana, Institut Pertanian Bogor, Bogor

[4] Indarjho, A., 2012. Strategi Pengembangan Ekowisata Bahari Berbasis Daya Dukung Lingkungan Di Pulau Panjang, Pantai Bandengan, Pantai Kartini, dan Teluk Awur Kabupaten Jepara. Disertasi. Sekolah Pascasarjana, Universitas Diponegoro, Semarang.

[5] Kamah, H.M., F.M. Sahami, dan S.N. Hamzah, 2013. Kesesuaian Wisata Pantai Berpasir Pulau Saronde Kecamatan Ponelo Kepulauan Kabupaten Gorontalo Utara. Jurnal Ilmu-Ilmu Pertanian 1 (1), pp. 1-15.

[6] Khairuman, 2007. Budidaya Patin Super. Agromedia Pustaka, Jakarta.

[7] Lestari, L.H., 2013. Komparasi karakteristik Pantai Peneluran Penyu (Kasus Pantai Pengumbahan dan Sindang Kerta Jawa Barat). Tesis. Sekolah pascasarjana, Universitas Padjajaran, Bandung.

[8] Nuraisyah, S., Sunatmo, dan Sarmintohadi, 2004. Pedoman Pengembangan Wisata Bahari Berbasis masyarakat di Kawasan Konservasi Laut. Direktorat Konservasi dan Taman Nasional Laut, Direktorat Jenderal Pesisir dan Pulau-Pulau Kecil, Departemen Kelautan dan Perikanan. Jakarta.

[9] Pusat Data dan Informasi Kementrian Pariwisata dan Kreatif Tahun 2011-2015.

[10] Sunarto, 1991. Geomorfologi Pantai. Disampaikan Dalam Kursus Singkat Pengelolaan Bangunan Pantai. Pusat Antar Universitas UGM, Yogyakarta.

[11] Surat Keputusan Bupati Batang, 2016. Salinan Lampiran Keputusan Bupati Batang Nomor 71 Tahun 2016. Tanggal 21 Desember 2015. 
[12] Suryadhi, 2013. Rancang Bangun Alat Ukur Kecepatan dan Arah Arus Laut Berbasis Mikrokontroller. Neptunus Jurnal Kelautan. 19(1), pp 1-12.

[13] Tambunan, J.M., S. Anggoro, H. Purnaweni, 2013. Kajian Kualitas Lingkungan dan Kesesuaian Wisata Pantai Tanjung Pesona Kabupaten Bangka. Prosiding Seminar Nasional Pengelolaan Sumberdaya Alam dan Lingkungan. Magister ilmu lingkungan, Universitas Diponegoro, Semarang.

[14] Umar, H., 2012. Metode Floating Object untuk Pengukuran Arus Menyusur Pantai. Jurnal Riset dan Teknologi Kelautan 10(2), pp. 157-167.
[15] Undang-Undang Nomor 10 Tahun 2009 Tentang Kepariwisataan.

[16] Yulianda, F., 2007. Ekowisata Bahari Sebagai Alternatif Pemanfaatan Sumberdaya Pesisir Berbasis Konservasi. Makalah. Departemen Manajemen Sumberdaya Perairan. Faultas Perikanan dan Ilmu Kelautan. Institut Pertanian Bogor, Bogor.

[17] Yulisa, N.K., Y. Johan, D. Hartono, 2016. Analisis Kesesuaian dan Daya Dukung Ekowisata Pantai Kategori Rekreasi Pantai Laguna Desa Merpas Kabupaten Kaur. Jurnal Enggano. 1(1), pp. 97-111. 